\title{
New Forms of vocal music students in colleges and universities to train thinking innovation
}

\author{
An Jie \\ The Silk Road Academy of Art, Weinan Normal University, Weinan, China, 714099 \\ Keywords: Higher Education; Vocal Music; Training \\ Abstract: The teaching of vocal music in institutions of higher learning is an artistic, \\ comprehensive, technical and highly specialized subject of higher music education. Vocal \\ music learning can effectively enhance the ability of physical, music mental, and cultural \\ comprehensive performance of course, these abilities of the students to exercise and \\ improve can not be separated from the guidance and training of teachers. In the new history \\ of higher education, it is imperative that we cultivate students who meet the requirements \\ of the times in the context of the development of higher education in a new historical era, \\ and a very important reality.
}

With the development of the times and the progress of society, people have more demand for the pursuit of spiritual world. The simultaneous development of spiritual civilization and material civilization construction has become the general direction of social development. Music can edify the sentiment of people, Polishing the character of human beings is an indispensable and important link in the construction of spiritual culture As the main position of vocal music cultivation in China, colleges and universities shoulder the task of cultivating high-quality vocal music talents for the country.

The vocal music teaching in colleges and universities of our country started relatively late, with its reform and development these years, we have made remarkable achievements in many aspects. At the same time, we should also see that the times are changing, society is changing, the requirements of higher education are changing, the demand of social development for talents is changing, and the ability literacy of individual talents is changing. How to deal with this change, to develop in the changing, to reform in the changing reform, to innovate in the changing innovation, this is not only a social problem, but also an educational problem. The teaching of vocal music in colleges and universities in China should actively adapt to this change. It is necessary to innovate in the teaching content of education and in the cultivation of students majoring in vocal music, and should not be rigid and old-fashioned.

\section{The problems existing in the teaching of vocal music in colleges and universities}

The continuous improvement and development of higher vocal music teaching in our country have not been solved effectively for years. It mainly boils down to the following aspects: 


\subsection{Talent Training Targets}

As a special specialty, the teaching of higher vocal music should have different talents cultivation goals when it is set up in different universities. In the present situation, the quality of vocal music training in colleges and universities is very difficult to cultivate. Professional Music Colleges and universities, the profession should be trained with professional level of musicians for the overall goal and general requirements for the cultivation of talent. For normal colleges and universities, the goal of personnel training should be more focused on students' comprehensive ability and comprehensive accomplishment. For example, in addition to mastering vocal music skills, students should also have extensive knowledge of teaching methods and related theory of vocal music, and should have the guiding ability of extracurricular activities.

\subsection{The contents of the teaching materials are not scientific}

Textbooks are an integral part of teaching and have a direct impact on the overall level of teaching. At this moment, the teaching material allocation of the vocal music major of our country's higher education, the whole situation can not be optimistic. In many colleges and universities, the teaching materials are old, the system is not perfect, many students feel a certain difficulty in the process of learning. This will not only discourage students to study enthusiasm and initiative, but also lose the significance and value of the teaching materials. At this point, many colleges and universities have, according to their professional conditions, organized their teachers to develop the ideas suitable for the development of the school, in line with the individualization of the students' learning rules, professional teaching materials and, in view of the practical results, have achieved very good results, has a great promotional value.

\subsection{The teaching method is backward}

The vocal music teaching in colleges and universities should be a lively teaching method, but many universities 'teaching methods, the teaching mode is limited to the traditional blackboard chalk, which makes the teaching atmosphere stiff and heavy, the teacher instilled knowledge into the students in the traditional way, and the teaching mode was basically one-size-fits-all and seldom took into account the students' own characteristics. This backward teaching method limits the development potential of students, constrains the students' thoughts, makes it difficult to inspire students in teaching, and stifles the students' creative consciousness

\subsection{Professional teachers are not well-rounded}

The vocal music-related courses in colleges and universities are highly specialized courses, which require the teachers to have very high professional quality. At present, some schools do not pay much attention to the construction of this specialty and discipline, and vocal music teachers are part-time teachers in other disciplines. On the whole, the problem of the poor quality of vocal music teachers in our country is quite outstanding. Many students also think less of vocal music courses. Teaching and learning are two factors which lead to the teaching quality of vocal music courses can not be effectively guaranteed. Because of the limitation of the conditions, some colleges and universities can not provide opportunities for teachers to pursue their studies and promotion, and teachers' knowledge and abilities have been raised slowly and their teaching enthusiasm is not high. 


\subsection{The wrong perception of light theory and heavy skills}

Many universities $d$ not start from the school orientation and the school practice, the school's vocal music teaching mode to Professional Music College. In the teaching of education, the emphasis is on the training of students' skills. Of course, we do not deny the importance of skills, but rather emphasize the importance of teaching for different people and for different people. Teachers' colleges have their own characteristics. Students majoring in vocal music in normal colleges and universities can easily lead to narrow vision if they focus only on vocal music skills, do not know basic theory, teaching theory and other knowledge, do not grasp the knowledge of the humanities, it is easy to lead to narrow vision, lack of comprehensive ability, for the future of the long-term development of hidden dangers.

\section{The cultivation of vocal music students in colleges and universities}

The training of vocal music students in colleges and universities should be combined with the requirements of the times and the construction of disciplines, coordinate and synchronize, and not be biased:

\subsection{Further clarification of teaching objectives}

In addition to requiring students to study in the aspects of vocal music theory, skill training and aesthetic appreciation, there are also very clear requirements for students in the teaching of vocal music, the outline requires students to master the basic ways and means of teaching, understand the characteristics of adolescents, have the relevant professional knowledge of vocalization practice and voice health care. Especially in normal colleges and universities, the vocal music profession should not solve the problem that the students will sing, but also let them master the ability of teaching. Our teaching objectives should be more specific, more scientific and more orderly, based on the syllabus and in strict accordance with the guidelines, to formulate practical teaching plans, curricula and so on, to ensure that every aspect of teaching and learning is informed, that efforts are made to eliminate the arbitrariness in teaching, to correct the wrong thinking of light teaching ability.

\subsection{Strengthen the teaching of theory}

Art Teaching is different from other fundamental science, and it is a fact that art teaching is difficult and difficult to learn. Because of the abstract nature of art, many things are expressed differently by different people, and different people have different understandings. The teaching of vocal music has its particularity, such as the acoustic source body's internal concealment, the subjective and objective hearing difference, the voice voice kind of complexity and so on, these are the difficulty of vocal music teaching. Nowadays, vocal music teaching in colleges and universities is not paying enough attention to the theoretical curriculum, and the vocal music theory curriculum is the weak link. In the future reform of teaching, we should strengthen the depth and breadth of theory teaching, so that students know how to sing and why to sing, and how to teach others to sing. We should strengthen the guiding role of theory knowledge to students, strengthen the ability of students to link theory with practice, feel practice in the theory learning, and promote the fit of theory and practice.

\subsection{Optimization of teaching forms}

One of the major achievements of the teaching reform of vocal music major in colleges and 
universities is to break the traditional single teaching form, and form the combination of large and medium and small, and complement each other. Because of the influence of the expansion of colleges and universities in our country, it is a realistic problem that many colleges and universities have to face. The organization form of vocal music teaching in colleges and universities is determined by the law of the course. The teaching mode of vocal music teaching in colleges and universities should be further optimized according to the school conditions. In the course of teaching vocal music and vocal music education and other common knowledge of the main, appropriate skills training. The small class mainly provides the practical platform for the students, the teaching progress can be adjusted according to the characteristics of students, so that the group of small classes is always in a reasonable state. In the lesson, teachers can discover and excavate the characteristics of the students, pay attention to the interest of students, and provide free development space for students.

\subsection{Cultivate Students' cultural literacy}

We should pay attention to the cultivation of the students 'cultural literacy. The improvement of the overall ability quality of the students' vocal music is invisible, but it is crucial. A singer who doesn't have a deep cultural upbringing to back him up will find it hard to Nothing in Common in the art world, at best. The development potential of this student is directly determined by the level of cultural literacy of a vocal music major. A good vocal professional talent only has a good voice and musicality is far from enough. Each person will have a different understanding of the different works of art, the basis of which is both related to each person's experience and is inextricably linked to the person's culture. But the foundation of culture is a long process, so we should let students know the importance of cultural literacy to individual development from the beginning, and cultivate the students' cultural literacy throughout the teaching of Education. Only in this way can we achieve the goal of improving students' ability as a whole. The one-sided, one-sided, one-sided teaching model that focuses on technology should be eradicated

\subsection{The emphasis is on strengthening the cultivation of students' aesthetic ability}

Music expresses not only thoughts, it is even the human spirit, the carrier of human emotion. The reason that music can move people is closely related to the carrier function of music. In vocal music teaching in colleges and universities, we should strengthen the cultivation of the students' aesthetic ability, guide the students into the life, experience the artistic situation, deepen the understanding of the works through emotional resonance, and complete the blending with the works. When teaching art, a vocal music teacher should give his own emotional judgment, let the students first understand the emotional factors contained in the works, and thus achieve a deep understanding of the work. The aesthetic education of vocal music teaching is not a process of simply letting students be accepted passively, but to find ways to motivate students to participate in the process of self-creation, to create, and ultimately to perceive, the work, to enhance their aesthetic taste.

\subsection{Deepen the application field of multimedia teaching}

Multimedia teaching is a powerful adjunct to traditional teaching. With the development of Information Technology, multimedia technology has penetrated into every corner of our working life. In the education teaching, we should also fully introduce the multimedia teaching mode, the traditional dull teaching content is vivid and flexible. At present, a variety of computer-based technology, communication technology, multimedia technology in the classroom and outside the teaching model is endless. For example, micro-classes, it is a good extra-curricular supplementary 
learning way, the teacher lectures the course to record, the student can carry on the continuous study in the after class, this way not only expands the teaching content, but also breaks the limitation of teaching condition. As the front and main position of our country's scientific research work, colleges and universities should be in the forefront of the field of information application, but at present, many colleges and universities still need to improve their informatization degree because of the investment of capital and the limitation of planning.

\subsection{Enhance the overall competency of teachers}

A qualified vocal music teacher should not only master the subject knowledge, educational teaching theory, but also understand the whole structure of knowledge, and pay attention to the professional personality edification. Under the background of Quality Education, the pressure of the teachers is much higher than before. Quality Education pays more attention to the overall competence literacy. Improving the overall quality of teachers is directly related to the success or failure of the liberal education. The details of knowledge are available to students in a variety of ways, but vocal skills and cultural skills are more accessible to students through the teacher's own upbringing and teaching.

\section{Conclusion}

With the continuous progress of the society, the demand for talents has also been raised. In the face of this challenge, we should constantly explore the problems in education and teaching, improve the teaching methods of education, and strive to improve the quality of the employees, improving students' overall abilities. This is not only the inherent requirement of the development of higher education in China, but also the necessary way for the development of vocal music profession itself.

\section{References}

[1] Xiao Ping, Ding Shuyue, the application of emotion in vocal music [J].Theatre House, 2017,01:58-59.

[2] Du Xue, the integration of traditional music culture in vocal music teaching [J]. Contemporary Music, 2017,01:25-26.

[3] Dan Xia, a brief analysis of the integration of traditional music culture in vocal music teaching in normal universities [J]. Arts Education, 2017, Z 2:90-91.

[4] Wu Jing the status and function of musicianship in the art of Vocal Music [J]. Art Review, 2017,02:70 -72.

[5] Cui Wenwen, on the re-creation of the performing art of Vocal Music [J]. Journal of Science, 2017,11:209-210.

[6] Zhi Hui, on the innovation of vocal music teaching mode [J]. Journal of the Suzhou, Anhui Institute of Education, 2017,02:160-161.

[7] Xiao Chuilan, the psychological interaction effect in primary vocal music teaching [j]. Art Review, 2017,05:100-102.

[8] Zhu Yanfeng, beauty of vocal music art in aesthetic perspective [J].Music Life,2017,04:81-82. 